\title{
Original
}

\section{Castability and mechanical properties of Ti-15Mo-5Zr-3Al alloy in dental casting}

\author{
Hiroyasu Koizumi ${ }^{1,2)}$, Takaya Ishii ${ }^{1,3)}$, Tomoyo Okazaki4), Masahiro Kaketani ${ }^{5,6)}$, \\ Hideo Matsumura ${ }^{1,2)}$, and Takayuki Yoneyama ${ }^{5,6}$
}

\author{
1)Department of Fixed Prosthodontics, Nihon University School of Dentistry, Tokyo, Japan \\ 2)Division of Advanced Dental Treatment, Dental Research Center, Nihon University School of Dentistry, \\ Tokyo, Japan \\ 3)Department of Oral and Maxillofacial Surgery, Juntendo Tokyo Koto Geriatric Medical Center, Tokyo, Japan \\ 4)Division of Applied Oral Sciences, Nihon University Graduate School of Dentistry, Tokyo, Japan \\ ${ }^{5)}$ Department of Dental Materials, Nihon University School of Dentistry, Tokyo, Japan \\ 6)Division of Biomaterials Science, Dental Research Center, Nihon University School of Dentistry, \\ Tokyo, Japan
}

(Received August 1, 2017; Accepted September 25, 2017)

\begin{abstract}
The castability, mechanical properties, and fracture characteristics of Ti-15Mo-5Zr-3Al alloy were compared with those of Ti-6Al-7Nb alloy and pure titanium (CPTi) for application of this $\beta$-type titanium alloy in cast dental prostheses. Cast specimens were prepared with a centrifugal casting machine. A tensile test was performed according to ISO standard 22674. The castability index for Ti-15Mo-5Zr-3Al was lower than those for Ti-6Al-7 Nb and CP Ti. The tensile strength of Ti-15Mo-5Zr-3Al was $852 \mathrm{MPa}$, which was lower than that of Ti-6Al-7Nb and higher than that of CP Ti. The proof strength of Ti-15Mo-5Zr-3Al was $799 \mathrm{MPa}$, which was comparable to that of Ti-6Al-7Nb and higher than that of $\mathrm{CP}$ Ti. The elastic modulus of Ti-15Mo-5Zr-3Al was 81.0 GPa, which was lower than the values for Ti-6Al-7Nb and CP Ti. Elongation of Ti-15Mo-5Zr-3Al was $5.1 \%$, which was comparable to that of Ti-6AI-7Nb and less than that of $\mathrm{CP}$ Ti. The shape of the fractured segment was narrower for Ti-15Mo-5Zr-3Al than for Ti-6Al-7Nb and CP Ti.
\end{abstract}

Correspondence to Dr. Hiroyasu Koizumi, Department of Fixed Prosthodontics, Nihon University School of Dentistry, 1-8-13 Kanda-Surugadai, Chiyoda-ku, Tokyo 101-8310, Japan Fax:+81-3-3219-8351 E-mail: koizumi.hiroyasu@nihon-u.ac.jp

Color figures can be viewed in the online issue at J-STAGE.

doi.org/10.2334/josnusd.17-0280

DN/JST.JSTAGE/josnusd/17-0280
The deformation characteristics of Ti-15Mo-5Zr-3Al may result in decreased stress relative to increased strain during plastic deformation in the stress-strain diagram. In conclusion, Ti-15Mo-5Zr-3Al alloy has a low elastic modulus and exhibits limited ductile plastic deformation in cast dental prostheses.

Keywords: castability; dental casting; elastic modulus; fracture surface; mechanical property; Ti-15Mo-5Zr-3Al alloy.

\section{Introduction}

Titanium is widely used for medical and dental treatments, because of its excellent corrosion resistance and biocompatibility $(1,2)$. However, since the mechanical strength of pure titanium is not sufficient (3), a+ $\beta$-type Ti-6Al-4V alloy was introduced for applications associated with high mechanical stress. Because of concerns regarding the cytotoxicity of vanadium $(\mathrm{V})$ in Ti-6Al-4V alloy, Ti-6Al-7Nb alloy, in which vanadium is replaced by niobium $(\mathrm{Nb})$, was developed for biomedical applications (4).

Titanium is used to cast dental prostheses. Titanium is much more reactive to oxygen than are conventional dental casting alloys; thus, special casting machines and mold materials have been developed for titanium casting (5-7). However, because pure titanium has disadvantages 
Table 1 Metals assessed in this study

\begin{tabular}{llll}
\hline Metal & Manufacturer & Lot number & Composition (mass\%) \\
\hline Ti-15Mo-5Zr-3Al & Kobe Steel Ltd. & $0639 F 63001$ & Ti:balance, Mo:15.0, Zr:5.0, Al:3.0 \\
Ti-6Al-7Nb & GC Corp. & 0702261 & Ti:86.5, Nb:7.0, Al:6.0, Fe+Ta:0.5, others \\
CP Ti (Grade 3) & GC Corp. & 070611 & Ti: $>99.2$, Fe: $<0.30$, others \\
\hline
\end{tabular}

as a dental casting material, such as a lack of mechanical strength (8), difficulties in polishing $(9,10)$, and poor wear resistance (11), Ti-6Al-7Nb alloy was introduced as a dental casting alloy $(8,11,12)$ and has been used clinically in various dental prostheses $(13,14)$.

Although numerous titanium alloys have been studied for dental casting $(5,15-18)$, only a $+\beta$-type Ti- $6 \mathrm{Al}-7 \mathrm{Nb}$ alloy has been used in clinical applications. Conversely, $\beta$-type titanium alloys, which have a low elastic modulus and high mechanical strength, have been extensively studied for surgical applications $(19,20)$. Ti-15Mo-5Zr$3 \mathrm{Al}$ alloy is a $\beta$-type titanium alloy used clinically as a surgical implant material and is standardized to International Standards Organization (ISO) specification 5832-14 (21). It was reported to have excellent corrosion resistance (22) and biocompatibility $(23,24)$ comparable to that of pure titanium. However, little is known about its properties as a dental casting material (25). The purpose of this study was to compare the castability, mechanical properties, and fracture characteristics of Ti-15Mo-5Zr$3 \mathrm{Al}$ alloy with those of $\mathrm{Ti}-6 \mathrm{Al}-7 \mathrm{Nb}$ alloy and pure titanium for application in cast dental prostheses.

\section{Materials and Methods}

\section{Materials}

Ti-15Mo-5Zr-3Al alloy (Kobe Steel Ltd., Kobe, Japan), Ti-6Al-7Nb alloy (T-Alloy Tough, GC Corp., Tokyo, Japan), and grade 3 commercially pure titanium (CP Ti, T-Alloy H, GC) were used to make cast specimens. The details of these materials are summarized in Table 1. The ingots were column shaped, $30 \mathrm{~mm}$ in diameter, $13 \mathrm{~mm}$ in height, and weighed approximately $30 \mathrm{~g}$.

\section{Castability test}

Mesh specimens were prepared to evaluate castability. Figure 1 shows the schematic configuration of the mesh wax pattern for casting. The wax pattern was prepared with a commercial wax mesh pattern for designing denture frameworks (Wax Retention No. 2, Shofu Inc., Kyoto, Japan). The cross-sectional shape of the line wax constituting the mesh pattern is a trapezoid, and the lengths of the parallel sides and height are $0.5,1.0$, and 0.8 $\mathrm{mm}$, respectively. These very thin meshes were chosen in order to provide a severe casting condition to classify the castability of the metals. The $30.5 \times 30.5 \mathrm{~mm}$ specimens contained 144 square openings formed by the meshes. These small square openings, referred to as segments, comprise the four sides of complete quadrilaterals. Wax bars with diameters of 3.0 and $2.2 \mathrm{~mm}$ were used for the sprues and runner bars, respectively.

The castability of each mesh specimen was calculated as the number of complete cast segments expressed as a percentage of the 144 total segments, which was defined as the castability index (12). Twelve specimens were used to evaluate the castability of each metal.

The wax pattern was invested in a mold ring by using a magnesia-based investment material (Selevest CB, Selec Co. Ltd., Osaka, Japan). The mold was made according to the manufacturer's instruction $(\mathrm{W} / \mathrm{P}$ ratio $=0.20)$. The distance between the top of the wax pattern and the top rim of the casting ring was set at approximately $10 \mathrm{~mm}$. Two hours after the wax pattern was invested, the mold was heated in an electric furnace (KDF-S80, Denken Co. Ltd., Kyoto, Japan) at a heating rate of $6^{\circ} \mathrm{C} / \mathrm{min}$ up to $850^{\circ} \mathrm{C}$, and kept at that temperature for $1 \mathrm{~h}$. It was then cooled to $120^{\circ} \mathrm{C}$ inside the furnace.

Casting was performed with a centrifugal casting machine (Ticast Super R, Selec), and the melting/casting chamber was evacuated to $7 \times 10^{-2} \mathrm{~Pa}$. The metal ingot was arc-melted $(210 \mathrm{~A}$, electrode distance $6 \mathrm{~mm})$ for $60 \mathrm{~s}$ in a high-purity argon atmosphere at a pressure of $2.8 \times$ $10^{4} \mathrm{~Pa}$ and cast into the mold. Castings were bench-cooled without removing the mold materials. The castings were cleaned with an ultrasonic washer and air-abraded with 50- to 70- $\mu \mathrm{m}$ alumina particles (Hi-Aluminas, Shofu) for 30 s (Jet Blast II, J. Morita Corp., Osaka, Japan) at an air pressure of $0.2 \mathrm{MPa}$.

\section{Tensile test}

The dumbbell-shaped wax patterns measured $3.0 \mathrm{~mm}$ in diameter and $20.0 \mathrm{~mm}$ in length at the parallel portion, and $6.0 \mathrm{~mm}$ in diameter and $10.0 \mathrm{~mm}$ in length at the chucking portion, in accordance with ISO 22674 (26). The specimens for the tensile test were cast in the same manner as those used in the castability test. After casting, all specimens had a perfect dumbbell shape, and no casting void was observed. The tensile test was carried out in accordance with ISO 22674 by using a 


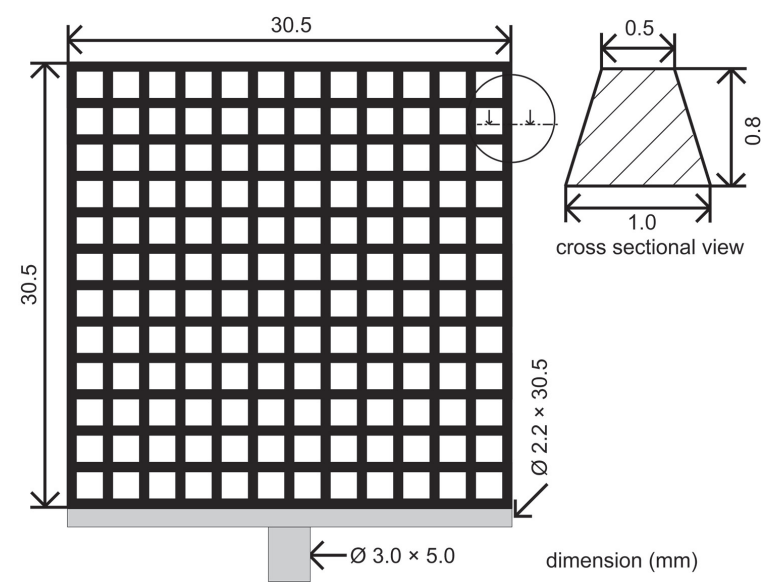

Fig. 1 Configuration of the mesh wax pattern.

universal testing machine (Model 5567, Instron, Canton, MA, USA) at a temperature of $23 \pm 1{ }^{\circ} \mathrm{C}$ and a relative humidity of $50 \pm 10 \%$ (26). Strain was detected with a non-contacting video extensometer (Advanced Video Extensometer, Instron). The gauge length was $15 \mathrm{~mm}$, and the cross-head speed was $1 \mathrm{~mm} / \mathrm{min}$.

Tensile strength, proof strength $(0.2 \%$ non-proportional strain), elastic modulus, and elongation were calculated from the obtained stress-strain diagrams. Nine specimens were used for each metal.

\section{Statistical analysis}

Statistical analyses were conducted by using statistical software (SPSS version 15.0, SPSS Inc., Chicago, IL, USA). The castability indices and tensile test results were analyzed primarily by the Kolmogorov-Smirnov test (SPSS). When the results of the Kolmogorov-Smirnov test did not exhibit a normal distribution in the groups, the Kruskal-Wallis test (SPSS) and Steel-Dwass multiple comparison test (Kyplot 5.0, KyensLab Inc., Tokyo, Japan) were performed. A $P$ value of less than 0.05 was considered to indicate statistical significance in all tests.

\section{Microscopic observation}

After tensile testing, the appearance of fractured specimens was observed with a digital photographic system (Nikon D200, Nikon Corp., Tokyo, Japan) at $\times 1.7$ magnification. Fractured surfaces were observed with a scanning electron microscope (SEM; S-4300, Hitachi High-Technologies Corp., Tokyo, Japan) operated at 15 $\mathrm{kV}$.

\section{Statistical analysis}

In the castability test, the Kolmogorov-Smirnov test of castability index results did not show a normal
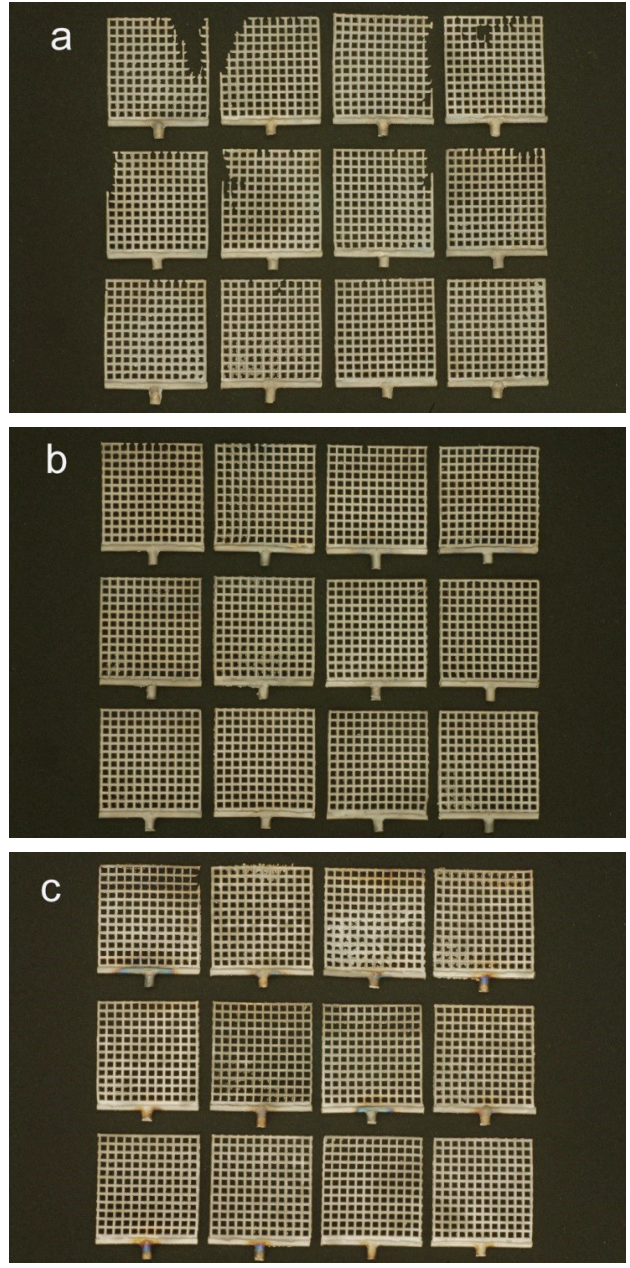

Fig. 2 Appearance of mesh cast specimens: (a) Ti-15Mo-5Zr3Al alloy, (b) Ti-6Al-7Nb alloy, (c) CP Ti.

distribution in the $\mathrm{CP} \mathrm{Ti}$ and $\mathrm{Ti}-6 \mathrm{Al}-7 \mathrm{Nb}$ groups. The Kruskal-Wallis test revealed significant differences in the castability index among the three groups $(P<0.001)$. In the tensile tests, the Kolmogorov-Smirnov test did not show a normal distribution in the elongation results. The Kruskall-Wallis test showed significant differences in tensile strength, proof strength, elastic modulus, and elongation values among the three groups $(P<0.001)$.

\section{Castability}

Figure 2 shows mesh cast specimens for Ti- $15 \mathrm{Mo}-5 \mathrm{Zr}-3 \mathrm{Al}$ alloy, Ti-6Al-7Nb alloy, and CP Ti. No Ti-15Mo-5Zr$3 \mathrm{Al}$ alloy specimen achieved complete casting (Fig. 2a), whereas several Ti-6Al-7Nb alloy specimens were completely cast, and all $\mathrm{CP}$ Ti specimens exhibited complete shapes (Fig. 2b, c).

The castability indices for the three metals, as evaluated by the ratio of the number of segments, are shown in Fig. 3 . The average index value was $93 \%$ for Ti- $15 \mathrm{Mo}-5 \mathrm{Zr}$ $3 \mathrm{Al}$ alloy, $99 \%$ for Ti-6Al-7Nb alloy, and approximately 


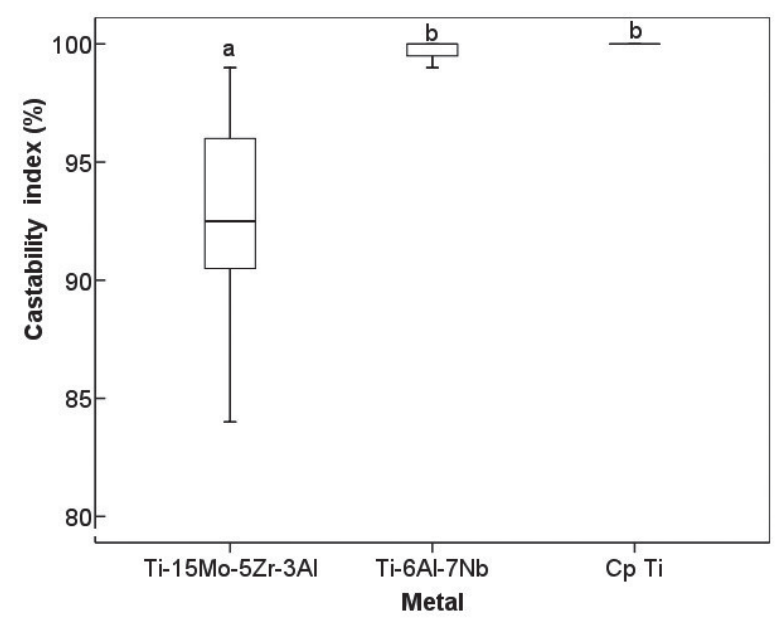

Fig. 3 Castability indices for mesh specimens of Ti-15Mo-5Zr$3 \mathrm{Al}$ alloy, Ti-6Al-7Nb alloy, and CP Ti. Identical letters indicate values that are not significantly different (Steel-Dwass multiple comparison test, $P>0.05$ ).

Table 2 Tensile strength of cast Ti-15Mo-5Zr-3Al alloy, Ti-6Al-7Nb alloy, and CP Ti

\begin{tabular}{lcccc}
\hline \multirow{2}{*}{ Metal } & \multicolumn{4}{c}{ Tensile strength (MPa) } \\
\cline { 2 - 5 } & Mean & Median & IQR & Category \\
\hline Ti-15Mo-5Zr-3Al & $852(21)$ & 848 & 36 & $\mathrm{~b}$ \\
Ti-6Al-7Nb & $943(18)$ & 945 & 19 & $\mathrm{c}$ \\
CP Ti & $579(13)$ & 586 & 19 & $\mathrm{a}$ \\
\hline
\end{tabular}

$n=9$; IQR, Interquartile range

Values in parentheses indicate standard deviations. Identical letters in the category indicate no significant difference $(P>0.05)$.

$100 \%$ for CP Ti. The Steel-Dwass nonparametric multiple comparison test showed a significantly lower castability index for Ti-15Mo-5Zr-3Al alloy (category a) than for Ti-6Al-7Nb alloy and CP Ti (category b).

\section{Tensile properties}

Figure 4 shows representative stress-strain diagrams for cast Ti-15Mo-5Zr-3Al alloy, Ti-6Al-7Nb alloy, and CP Ti. The stress-strain relationships for Ti-15Mo-5Zr-3Al alloy, Ti-6Al-7Nb alloy, and CP Ti were nearly proportional up to approximately $700 \mathrm{MPa}, 800 \mathrm{MPa}$, and 400 $\mathrm{MPa}$, respectively. The slope of stress per strain in this range was lowest for Ti-15Mo-5Zr-3Al alloy. When stress exceeded the proportional limit, the increase in stress per strain gradually decreased for the three metals; however, the increase in stress decreased more rapidly for Ti-15Mo-5Zr-3Al alloy than for Ti-6Al-7Nb alloy and $\mathrm{CP}$ Ti.

Table 2 shows the tensile strengths of cast Ti-15Mo-5Zr-3Al alloy, Ti-6Al-7Nb alloy, and CP Ti. Tensile strength values significantly differed among the metals.

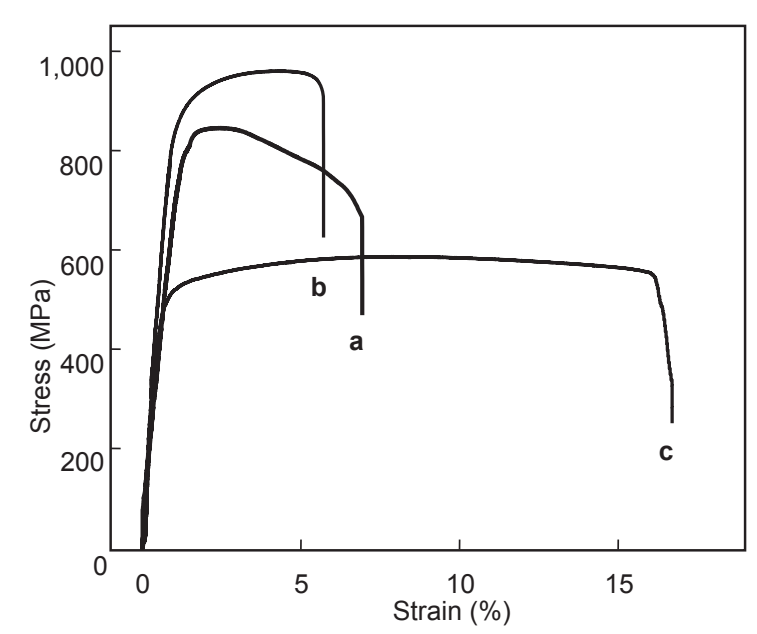

Fig. 4 Typical stress-strain diagrams for cast (a) Ti-15Mo-5Zr$3 \mathrm{Al}$ alloy, (b) Ti-6Al-7Nb alloy, and (c) CP Ti.

Table 3 Proof strength of cast Ti-15Mo-5Zr-3Al alloy, Ti-6Al-7Nb alloy, and CP Ti

\begin{tabular}{lcccc}
\hline \multirow{2}{*}{ Metal } & \multicolumn{4}{c}{ Proof strength (MPa) } \\
\cline { 2 - 5 } & Mean & Median & IQR & Category \\
\hline Ti-15Mo-5Zr-3Al & $799(22)$ & 796 & 39 & $\mathrm{~b}$ \\
Ti-6Al-7Nb & $816(16)$ & 820 & 15 & $\mathrm{~b}$ \\
CP Ti & $494(15)$ & 492 & 20 & $\mathrm{a}$ \\
\hline
\end{tabular}

$n=9$; IQR, Interquartile range; $\mathrm{SD}$, standard deviation

Values in parentheses indicate standard deviations. Identical letters in the category indicate no significant difference $(P>0.05)$.

Table 3 shows the proof strengths determined with $0.2 \%$ non-proportional strain of cast Ti-15Mo-5Zr-3Al alloy, Ti-6Al-7Nb alloy, and CP Ti. Proof strength values were not significantly different between Ti- $15 \mathrm{Mo}-5 \mathrm{Zr}-$ $3 \mathrm{Al}$ alloy and $\mathrm{Ti}-6 \mathrm{Al}-7 \mathrm{Nb}$ alloy; however, the proof strength of CP Ti was significantly lower than those of Ti-15Mo-5Zr-3Al alloy and Ti-6Al-7Nb alloy.

Table 4 shows the elastic moduli of cast Ti-15Mo-5Zr$3 \mathrm{Al}$ alloy, Ti-6Al-7Nb alloy, and $\mathrm{CP}$ Ti. Elastic moduli were not significantly different between $\mathrm{CP}$ $\mathrm{Ti}$ and $\mathrm{Ti}-6 \mathrm{Al}-7 \mathrm{Nb}$ alloy, but the elastic modulus of Ti-15Mo-5Zr-3Al alloy was significantly lower than those of CP Ti and Ti-6Al-7Nb alloy.

Table 5 shows elongation values for cast Ti- $15 \mathrm{Mo}-5 \mathrm{Zr}-$ $3 \mathrm{Al}$ alloy, Ti-6Al-7Nb alloy, and $\mathrm{CP}$ Ti. Elongation values were not significantly different between Ti- $15 \mathrm{Mo}-5 \mathrm{Zr}$ $3 \mathrm{Al}$ alloy and $\mathrm{Ti}-6 \mathrm{Al}-7 \mathrm{Nb}$ alloy, but the elongation value for $\mathrm{CP} \mathrm{Ti}$ was significantly higher than those for Ti-15Mo-5Zr-3Al alloy and Ti-6Al-7Nb alloy.

Fractured section and surface after the tensile test Figure 5 shows fractured specimens of cast Ti- $15 \mathrm{Mo}-5 \mathrm{Zr}-$ 
Table 4 Elastic moduli of cast Ti-15Mo-5Zr-3Al alloy, Ti-6Al-7Nb alloy, and CP Ti

\begin{tabular}{lcrrc}
\hline \multirow{2}{*}{ Metal } & \multicolumn{4}{c}{ Elastic modulus (GPa) } \\
\cline { 2 - 5 } & Mean & Median & \multicolumn{1}{c}{ IQR } & Category \\
\hline Ti-15Mo-5Zr-3Al & $81.0(14.9)$ & 81.4 & 25.5 & a \\
Ti-6Al-7Nb & $106.3(6.7)$ & 105.2 & 9.4 & b \\
CP Ti & $97.4(13.3)$ & 98.4 & 13.6 & b \\
\hline
\end{tabular}

$n=9$; IQR, Interquartile range

Values in parentheses indicate standard deviations. Identical letters in the category indicate no significant difference $(P>0.05)$.
Table 5 Elongation of cast Ti-15Mo-5Zr-3Al alloy, Ti-6Al-7Nb alloy, and CP Ti

\begin{tabular}{lcccc}
\hline \multirow{2}{*}{ Metal } & \multicolumn{4}{c}{ Elongation (\%) } \\
\cline { 2 - 5 } & \multicolumn{1}{c}{ Mean } & Median & IQR & Category \\
\hline Ti-15Mo-5Zr-3Al & $5.1(3.0)$ & 4.8 & 4.3 & a \\
Ti-6Al-7Nb & $5.8(2.8)$ & 5.7 & 5.1 & a \\
CP Ti & $11.6(2.7)$ & 11.0 & 3.5 & b \\
\hline
\end{tabular}

$n=9$; IQR, Interquartile range

Values in parentheses indicate standard deviations. Identical letters in the category indicate no significant difference $(P>0.05)$.
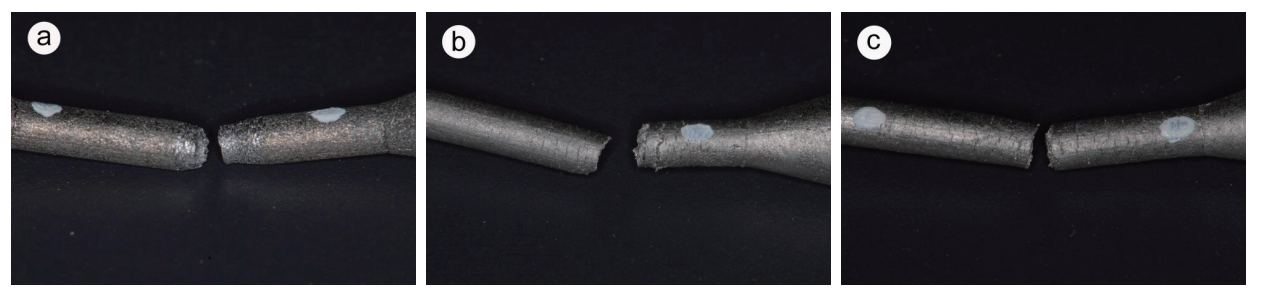

Fig. 5 Appearance of fractured specimens of cast (a) Ti-15Mo-5Zr-3Al alloy, (b) Ti-6Al-7Nb alloy, and (c) CP Ti after a tensile test.
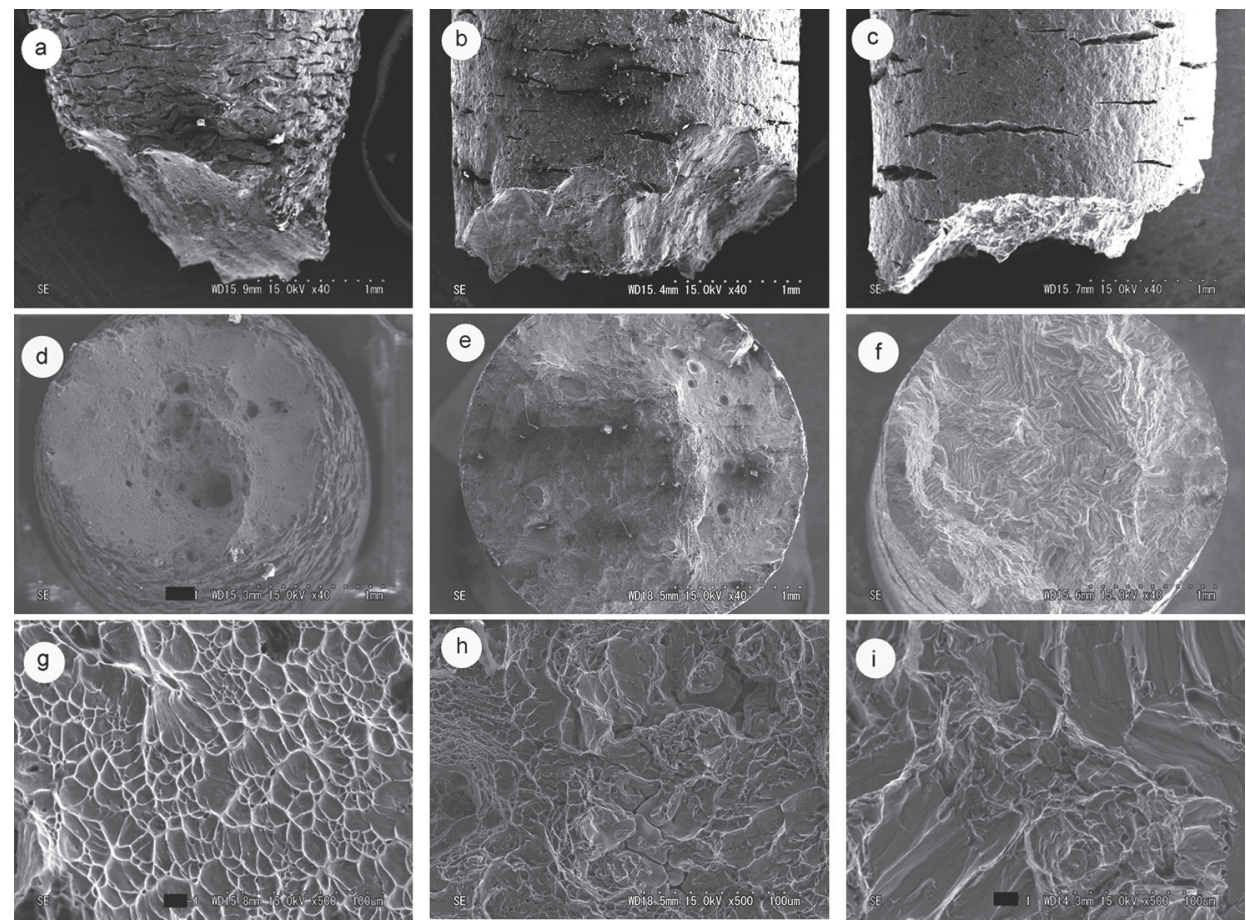

Fig. 6 SEM images of fractured sections and surfaces of cast specimens after the tensile test. Side views (low magnification $\times 40$ ): (a) Ti-15Mo-5Zr-3Al alloy (b) Ti-6Al-7Nb alloy, and (c) CP Ti. Fractured surfaces (low magnification $\times 40$ ): (d) Ti-15Mo-5Zr-3Al alloy, (e) Ti-6Al-7Nb alloy, and (f) CP Ti. Fractured surfaces (high magnification $\times 500$ ): (g) Ti-15Mo-5Zr-3Al alloy, (h) Ti-6Al-7Nb alloy, and (i) CP Ti.

3Al alloy, Ti-6Al-7Nb alloy, and $\mathrm{CP} \mathrm{Ti}$ after the tensile test. The shape of the fractured section of the Ti-15Mo-5Zr-3Al alloy was narrower and more tapered than those of the Ti-6Al-7Nb alloy and CP Ti.

Figure 6 shows SEM images of the fractured sections and surfaces of cast Ti-15Mo-5Zr-3Al alloy, Ti-6Al-7Nb alloy, and CP Ti after tensile testing. Side views of the fractured sections show many thin cracks at the narrowed fractured section of Ti-15Mo-5Zr-3Al alloy (a), while cracks in the Ti-6Al-7Nb alloy (b) and CP Ti (c) were less numerous and coarser. In low-magnification images of fractured surfaces, the cross-sectional fractured area 
of Ti-15Mo-5Zr-3Al alloy (d) was less than those of Ti-6Al-7Nb alloy (e) and CP Ti (f), i.e., the reduction area was higher for Ti-15Mo-5Zr-3Al alloy than for Ti-6Al-7Nb alloy and CP Ti. In high-magnification images of fractured surfaces, a clear dimple pattern was observed on the fractured surface of Ti-15Mo-5Zr-3Al alloy $(\mathrm{g})$ but was not apparent on the fractured surface of Ti-6Al-7Nb alloy (h). A river pattern was observed on the fractured surface of CP Ti (i).

\section{Discussion}

Castability is an essential property for dental casting alloys and is affected by many factors, including the composition, permeability, and temperature of the mold; the melting atmosphere, heating conditions, and casting pressure of the casting machine; and the melting temperature and fluid properties of the metal. On the basis of the present castability test results, casting conditions were satisfactory for $\mathrm{CP} \mathrm{Ti}$ and Ti-6Al-7Nb alloy, which had high castability indices. However, the castability index for Ti-15Mo-5Zr-3Al alloy was lower than those for Ti-6Al-7Nb alloy and CP Ti.

The decreased castability of Ti-15Mo-5Zr-3Al alloy may be related to differences in the compositional elements of the three metals. Molybdenum and zirconium are included only in Ti-15Mo-5Zr-3Al alloy and are added as $\beta$-phase stabilizers $(27,28)$. Addition of $5 \%$ molybdenum or zirconium to titanium caused a decrease in castability in a graphite mold (29). Therefore, the inclusion of molybdenum and zirconium in Ti-15Mo-5Zr-3Al alloy probably decreased castability. In the binary Ti-Mo system, alloy castings are predominantly $\beta$ phase when molybdenum content is $10 \%$ or higher (27). A previous study reported that addition of niobium - a $\beta$-phase stabilizer for titanium-decreased castability (29). The slight decrease in the castability of Ti-6Al-7Nb alloy as compared with CP Ti may be attributable to this factor. One reason for the decrease in castability caused by the presence of additional elements is the difference in the fluidity of molten metal. The flow configuration of a molten pure metal differs from that of a molten alloy (30), and the fluidity of an alloy is generally lower than that of a pure metal (12). The castability index of the Ti-15Mo-5Zr-3Al alloy was lower than those of Ti-6Al-7Nb alloy and CP Ti in this study. Because the present casting condition is intended for casting of Ti-6Al-7Nb alloy and $\mathrm{CP} \mathrm{Ti}(8)$, the properties of molten Ti-15Mo-5Zr-3Al alloy may not be suitable for casting. Reza et al. reported that titanium castability was significantly affected by casting conditions (31). Therefore, castability might be improved by changing casting conditions, such as melting time, arc voltage, or electrode distance, for Ti-15Mo-5Zr-3Al alloy.

Biological and mechanical biocompatibility are the two primary factors in the development of titanium alloys for biomedical applications. Three wrought titanium alloys for surgical implants are listed in the international standard: Ti-6Al-4V (ISO 5832-3), Ti-5Al-2.5Fe (ISO 5832-10), and Ti-6Al-7Nb (ISO 5832-11) alloys (32-34). The first is an a+ $\beta$-type titanium alloy, and the other two were developed to eliminate cytotoxic vanadium from Ti-6Al-4V alloy (3). To improve the mechanical biocompatibility of titanium alloys, $\beta$-type titanium alloys were developed, such as Ti-13Nb-13Zr alloy and Ti-12Mo-6Zr-2Fe, Ti-15Mo, and Ti-15Mo-5Zr-3Al alloys. The elastic moduli of these $\beta$-type wrought titanium alloys are lower than those of pure titanium and a $+\beta$-type titanium alloys but still higher than that of bone (19). Although some $\beta$-type titanium alloys have been studied for dental casting $(15,17,18)$, none is clinically available for dental cast prostheses.

The tensile strength of cast Ti-15Mo-5Zr-3Al alloy was $852 \mathrm{MPa}$, which was slightly lower than that of Ti-6Al-7Nb alloy (Table 2). Because the data are consistent with those obtained from wrought specimens of these alloys (19), the tensile strengths of these alloys did not seem to be affected by the present casting process. No significant difference was observed between the proof strengths of Ti-15Mo-5Zr-3Al and Ti-6Al-7Nb alloys (Table 3). Therefore, the difference between tensile strength and proof strength was small for Ti- $15 \mathrm{Mo}-5 \mathrm{Zr}-$ $3 \mathrm{Al}$ alloy. A possible reason for this property is the deformation characteristics of Ti-15Mo-5Zr-3Al alloy. As shown in Fig. 4, the increase in stress per strain gradually decreased after the stress exceeded the proportional limit for the three metals. In the case of Ti- $15 \mathrm{Mo}-5 \mathrm{Zr}$ $3 \mathrm{Al}$ alloy, the maximum stress value was reached at a lower strain, as compared with the other two metals, and considerably decreased as strain increased in the plastic deformation range. Because of this plastic deformation characteristic, the tensile strength of Ti- $15 \mathrm{Mo}-5 \mathrm{Zr}-3 \mathrm{Al}$ alloy may not greatly increase after proof strength; consequently, tensile strength was slightly higher than the proof strength of this alloy.

Previous studies described the elastic moduli of dental casting alloys in tensile testing, e.g., 95 to $100 \mathrm{GPa}$ for gold alloys with hardening heat treatment (35) and 218 GPa for vitallium, a Co-Cr alloy (36). In a four-point bending test, the elastic moduli of a gold alloy, Ti-6Al-7Nb alloy, and grade 2 commercially pure titanium were 94.1 $\mathrm{GPa}, 105.3 \mathrm{GPa}$, and 108.2 GPa, respectively (37). The elastic moduli of cast Ti-6Al-7Nb alloy and $\mathrm{CP} \mathrm{Ti}$ in the 
present study (Table 4) were within the range of previously reported values $(19,37)$, comparable to those of gold alloys, and much lower than those of Co-Cr alloys. The elastic modulus of the cast Ti-15Mo-5Zr-3Al alloy was $81.0 \mathrm{GPa}$, which is significantly lower than those of Ti-6Al-7Nb alloy and CP Ti in this study (Table 4). Because this value is consistent with that reported for the wrought $\mathrm{Ti}-15 \mathrm{Mo}-5 \mathrm{Zr}-3 \mathrm{Al}$ alloy $(12,24,38)$, the low elastic modulus of Ti-15Mo-5Zr-3Al alloy was likely maintained after the dental casting process in this study.

Elongation of cast Ti-15Mo-5Zr-3Al alloy was comparable to that of Ti-6Al-7Nb alloy and less than that of CP Ti (Table 5). These results are consistent with the elongation values of these metals in the wrought condition (19); however, the elongation values for the three metals in this study were considerably lower than those of the wrought metals. This deterioration in elongation is likely caused by oxidization and reactions with mold materials $(5,6)$.

After the present tensile test, the fractured sections of Ti-15Mo-5Zr-3Al alloy specimens were narrower than those of Ti-6Al-7Nb alloy and CP Ti (Fig. 5). The narrowed fracture section and reduced cross-sectional fracture area of Ti-15Mo-5Zr-3Al alloy are shown in Fig. $6 \mathrm{a}$ and $\mathrm{d}$. The narrow fracture section and reduced crosssectional fractured area indicate continuous narrowing of a section of the specimen in the tensile test, which may cause a decrease in stress relative to increased strain during plastic deformation, as shown in Fig. 4. When the cross-sectional area of a section of a specimen decreases in the tensile test, the stress value in a nominal stress-strain diagram decreases because nominal stress is calculated by the following formula,

$$
\sigma_{\mathrm{n}}=W / A_{0}
$$

where $\sigma_{\mathrm{n}}$ is nominal stress, $W$ is load, and $A_{0}$ is the original cross-sectional area of the specimen.

In a SEM image of the fractured surface of Ti-15Mo-5Zr-3Al alloy, a clear dimple pattern was observed (Fig. 6g), which is a characteristic microstructural feature of a ductile fracture in a material. Conversely, flat planes and straight lines, referred to as a river pattern, were observed in the fractured surface of CP Ti (Fig. 6i) and are a typical finding in a cleavage fracture of a material. In the fractured surface of Ti-6Al-7Nb alloy, neither a dimple pattern nor a river pattern was observed (Fig. $6 \mathrm{~h})$. Although the elongation of Ti-15Mo-5Zr-3Al alloy was lower than that of $\mathrm{CP} \mathrm{Ti}$, this ductile fracture pattern of Ti-15Mo-5Zr-3Al alloy is possibly caused by the $\beta$-phase characteristics (2) of this alloy. In conclusion, Ti-15Mo-5Zr-3Al alloy has a low elastic modulus and exhibits limited ductile plastic deformation in cast dental prostheses.

\section{Acknowledgments}

This work was supported in part by a grant from the Dental Research Center, Nihon University School of Dentistry (2013 and 2015).

\section{Conflict of interest}

None of the authors has any conflict of interest regarding this article.

\section{References}

1. Nakajima H, Okabe T (1996) Titanium in dentistry: development and research in the U.S.A. Dent Mater J 15, 77-90.

2. Long M, Rack HJ (1998) Titanium alloys in total joint replacement--a materials science perspective. Biomaterials $19,1621-1639$.

3. Niinomi M (2008) Metallic biomaterials. J Artif Organs 11, 105-110.

4. Semlitsch MF, Weber H, Streicher RM, Schon R (1992) Joint replacement components made of hot-forged and surfacetreated Ti-6Al-7Nb alloy. Biomaterials 13, 781-788.

5. Ida K, Togaya T, Tsutsumi S, Takeuchi M (1982) Effect of magnesia investments in the dental casting of pure titanium or titanium alloys. Dent Mater J 1, 8-21.

6. Hamanaka H, Doi H, Yoneyama T, Okuno O (1989) Dental casting of titanium and Ni-Ti alloys by a new casting machine. J Dent Res 68, 1529-1533.

7. Takahashi J, Kimura H, Lautenschlager EP, Chern Lin JH, Moser JB, Greener EH (1990) Casting pure titanium into commercial phosphate-bonded $\mathrm{SiO}_{2}$ investment molds. J Dent Res 69, 1800-1805.

8. Kobayashi E, Wang TJ, Doi H, Yoneyama T, Hamanaka H (1998) Mechanical properties and corrosion resistance of Ti-6Al-7Nb alloy dental castings. J Mater Sci Mater Med 9, 567-574.

9. Shimakura M, Yamamoto M, Nakajima K, Yoshida N (2000) Application of a centrifugal shooting type polishing system to polish pure titanium. Dent Mater J 19, 405-412.

10. Hirata T, Nakamura T, Takashima F, Maruyama T, Taira M, Takahashi J (2001) Studies on polishing of Ti and Ag-Pd$\mathrm{Cu}-\mathrm{Au}$ alloy with five dental abrasives. J Oral Rehabil 28, 773-777.

11. Iijima D, Yoneyama T, Doi H, Hamanaka H, Kurosaki N (2003) Wear properties of Ti and Ti-6Al-7Nb castings for dental prostheses. Biomaterials 24, 1519-1524.

12. Wang TJ, Kobayashi E, Doi H, Yoneyama T (1999) Castability of Ti-6Al-7Nb alloy for dental casting. J Med Dent Sci 46, 13-19.

13. Matsumura H, Yoneyama T, Shimoe S (2002) Veneering technique for a Ti-6Al-7 $\mathrm{Nb}$ framework used in a resin-bonded fixed partial denture with a highly filled indirect composite. J Prosthet Dent 88, 636-639.

14. Srimaneepong V, Yoneyama T, Wakabayashi N, Kobayashi 
E, Hanawa T, Doi H (2004) Deformation properties of Ti-6A1-7Nb alloy castings for removable partial denture frameworks. Dent Mater J 23, 497-503.

15. Takahashi M, Kikuchi M, Takada Y, Okuno O (2002) Mechanical properties and microstructures of dental cast Ti-Ag and Ti-Cu alloys. Dent Mater J 21, 270-280.

16. Takahashi M, Kikuchi M, Takada Y, Okuno O, Okabe T (2004) Corrosion behavior and microstructures of experimental Ti-Au alloys. Dent Mater J 23, 109-116.

17. Takemoto S, Hattori M, Yoshinari M, Kawada E, Asami K, Oda Y (2004) Corrosion behavior and surface characterization of Ti-20Cr alloy in a solution containing fluoride. Dent Mater J 23, 379-386.

18. Niinomi M, Akahori T, Takeuchi T, Katsura S, Fukui H, Toda H (2005) Mechanical properties and cyto-toxicity of new beta type titanium alloy with low melting points for dental applications. Mater Sci Eng C 25, 417-425.

19. Niinomi M (1998) Mechanical properties of biomedical titanium alloys. Mater Sci Eng A 243, 231-236.

20. Niinomi M (2008) Mechanical biocompatibilities of titanium alloys for biomedical applications. J Mech Behav Biomed Maters 1, 30-42.

21. International Organization for Standardization (2007) Implants for surgery--Metallic materials--Part 14: Wrought titanium 15-molybdenum 5-zirconium 3-aluminium alloy. ISO 5832-14:2007, Geneve.

22. Nakayama Y, Yamamuro T, Kotoura Y, Oka M (1989) In vivo measurement of anodic polarization of orthopaedic implant alloys: comparative study of in vivo and in vitro experiments. Biomaterials 10, 420-424.

23. Ungersbock A, Perren SM, Pohler O (1994) Comparison of the tissue reaction to implants made of a beta titanium alloy and pure titanium. Experimental study on rabbits. J Mater Sci Mater Med 5, 788-792.

24. Matsuda Y, Nakamura T, Ido K, Oka M, Okumura H, Matsushita T (1997) Femoral component made of Ti-15Mo-5Zr-3Al alloy in total hip arthroplasty. J Orthop Sci 2, 166-170.

25. Kochi M, Koizumi H, Murakami M, Kikuchi H, Matsumura $\mathrm{H}$, Yoneyama $\mathrm{T}$ (2011) Hardness and microstructure of Ti-15Mo-5Zr-3Al alloy for dental casting. Acta Odontol Scand 69, 328-333.
26. International Organization for Standardization (2006) Dentistry--Metallic materials for fixed and removable restorations and appliances. ISO 22674:2006, Geneve.

27. Ho WF, Ju CP, Lin JH (1999) Structure and properties of cast binary Ti-Mo alloys. Biomaterials 20, 2115-2122.

28. Guillemot F (2005) Recent advances in the design of titanium alloys for orthopedic applications. Expert Rev Med Devices 2, 741-748.

29. Cheng WW, Ju CP, Lin JH (2007) Structure, castability and mechanical properties of commercially pure and alloyed titanium cast in graphite mould. J Oral Rehabil 34, 528-540.

30. Takahashi J, Zhang JZ, Okazaki M (1993) Effect of casting methods on castability of pure titanium. Dent Mater J 12, 245-252.

31. Reza F, Takahashi H, Iwasaki N, Tamaki Y (2010) Effects of investment type and casting system on permeability and castability of CP titanium. J Prosthet Dent 104, 114-121.

32. International Organization for Standardization (2016) Implants for surgery--Metallic materials--Part 3: Wrought titanium 6-aluminium 4-vanadium alloy. ISO 5832-3:2016, Geneve.

33. International Organization for Standardization (1996) Implants for surgery--Metallic materials--Part 10: Wrought titanium 5-aluminium 2,5-iron alloy. ISO 5832-10:1996, Geneve.

34. International Organization for Standardization (2014) Implants for surgery--Metallic materials--Part 11: Wrought titanium 6-aluminium 7-niobium alloy. ISO 5832-11:2014, Geneve.

35. Oilo G, Gjerdet NR (1983) Dental casting alloys with a low content of noble metals: physical properties. Acta Odontol Scand 41, 111-116.

36. Morris HF, Asgar K (1975) Physical-properties and microstructure of 4 new commercial partial denture alloys. J Prosthet Dent 33, 36-46.

37. Suansuwan N, Swain MV (2001) Determination of elastic properties of metal alloys and dental porcelains. J Oral Rehabil 28, 133-139.

38. Maehara K, Doi K, Matsushita T, Sasaki Y (2002) Application of vanadium-free titanium alloys to artificial hip joints. Mater Trans 43, 2936-2942. 